\title{
Localization of Acidic Fibroblast Growth Factor in Specific Subcortical Neuronal Populations
}

\author{
Angela Stock,' Karl Kuzis,' William R. Woodward, ${ }^{2}$ Rae Nishi,' and Felix P. Eckenstein ${ }^{1,2}$ \\ Departments of ${ }^{1}$ Cell Biology and Anatomy and ${ }^{2}$ Neurology, Oregon Health Sciences University, Portland, Oregon 97201
}

The effects of fibroblast growth factors (FGFs) in vitro include the stimulation of mitogenesis in a variety of nonneuronal cell types and the promotion of the survival of various central and peripheral neuronal populations. The precise physiological role of FGFs in vivo is currently not known. As a step toward understanding the role of FGFs in the nervous system, the present study determined the distribution of acidic FGF (aFGF) in the rat CNS. The levels of aFGF in dissected areas of the nervous system were quantified using a biological assay method, and the cellular distribution of aFGF was determined in tissue sections using immunohistochemical methods. aFGF was found to be localized within specific neuronal populations in the CNS and was absent from non-neuronal cells. Neurons containing aFGF immunoreactivity included magnocellular neurons in the septal area and nucleus basalis; some additional defined neuronal groups in the subcortical telencephalon; specific neuronal populations in the hypothalamus, the thalamus, the substantia nigra, the reticular formation, and the pons; and motor and sensory neurons. Cerebral cortex and hippocampus contained only a very limited number of aFGF-immunoreactive neurons. A significant overlap of neuronal populations known to express the low-affinity NGF receptor (LNGFR) with populations containing aFGF immunoreactivity was also observed. These neuronal populations are known to be affected by neurodegenerative diseases, and the possible functional implications of the presence of aFGF and the LNGFR in these cells are discussed.

Heparin binding growth factors include the family of fibroblast growth factors (FGFs) that stimulate mitogenesis in a wide variety of cell types of mesodermal or neuroectodermal origin. The best-studied members of the FGF family are acidic FGF (aFGF) and basic FGF (bFGF; see Burgess and Maciag, 1989, for review), but additional members of this family [HST (Taira et al., 1987), Int-2 (Moore et al., 1986), FGF-5 (Zhan et al., 1988), FGF-6 (Marics et al., 1989), and KGF (Marchese et al., 1990)] have been identified. All members of this family show substantial amino acid sequence homology (roughly $50 \%$ sequence identity) in their core regions.

\footnotetext{
Received Mar. 6, 1992; revised June 12, 1992; accepted June 16, 1992.

We are grateful to M. Coulombe, T. E. Williams, and T. Holbert for expert technical assistance, and we thank T. Finn for help with the expression of recombinant aFGF. This work was supported by NIH Grants AG07424, NS17493 (F.P.E.), NS25767 (R.N.); by a March of Dimes Research Grant (F.P.E.); and by a grant from the Medical Research Foundation of Oregon (W.R.W.).

Correspondence should be addressed to Felix P. Eckenstein, Department of Cell Biology and Anatomy, Oregon Health Sciences University, 3181 SW Sam Jackson Park Road, Portland, OR 97201.

Copyright (c) 1992 Society for Neuroscience $0270-6474 / 92 / 124688-13 \$ 05.00 / 0$
}

A number of recent studies investigating the action of FGFs on neuroectodermally derived cells in vitro revealed that these growth factors can serve a pleiotropic role. For example, FGFs are potent mitogens for astrocytes (Pettmann et al., 1985), oligodendrocytes (Eccleston and Silberberg, 1985), and Schwann cells (Davis and Stroobant, 1990), and they promote the survival or fiber outgrowth of postmitotic neurons dissociated from cerebral cortex (Morrison et al., 1986), hippocampus (Walicke et al., 1986), retina (Lipton et al., 1988), cerebellum (Hatten et al., 1988), the septal area (Grothe et al., 1989), the ciliary ganglion (Schubert et al., 1987; Unsicker et al., 1987; Eckenstein et al., 1990), and sympathetic and sensory ganglia (Eckenstein et al., 1990). Taken together, these observations suggest that FGFs may be of importance for the development and maintenance of nervous tissue. Additional support for this suggestion comes from studies demonstrating that FGFs are present in relatively high levels in brain (Gospodarowicz et al., 1987; Burgess and Maciag, 1989), with aFGF and bFGF possibly being the principle mitogenic factors extracted from adult brain (Thomas, 1987; Eckenstein et al., 1991b). Cell surface FGF receptors that span the cell membrane and contain tyrosine kinase motifs are also widely expressed throughout the nervous system (Heuer et al., 1990; Wanaka et al., 1990; Partanen et al., 1991), and it appears likely that, in order to be biologically active, FGFs have to be presented to these receptors by specific heparan proteoglycans (Rapracger ct al., 1991; Yayon ct al., 1991).

The specific functions of individual members of the FGF family in the nervous system in vivo are not well understood, mainly for the following reasons. First, the pleiotropic actions of FGFs seen in vitro may be more restricted in vivo. For example, adult CNS contains substantial levels of FGFs, but significant mitosis of non-neuronal cells, such as astrocytes, is not observed in normal adult CNS. Second, aFGF and bFGF lack traditional signal peptide sequence (Burgess and Maciag, 1989) thought to be necessary for efficient secretion (Walter and Lingappa, 1986). Indeed, it has been speculated that the mechanism making aFGF or bFGF available in the extracellular space might determine the specific physiological role of these factors. Third, recent evidence suggests that FGFs have a direct intracellular function within the cells expressing the factors, possibly by a direct effect of FGFs on gene transcription within the nucleus (Baldin et al., 1990; Amalric et al., 1991).

Knowing which cell types within the CNS contain different FGF family members is important for gaining insight into the physiological role of FGFs in this tissue. We had earlier reported that the ratio of aFGF to bFGF varies considerably in extracts prepared from different areas of the nervous system (Eckenstein et al., 1991b). Using a combination of immunohistochemical, biological, and Western blot methods, we then showed that bFGF is present in both the nucleus and cytoplasm of astrocytes 
and CA2 hippocampal neurons (Woodward et al., 1992), whereas aFGF activity is most abundant in peripheral axons and sensory neurons (Eckenstein et al., 1991a). In addition, aFGF immunoreactivity has been reported in both sensory and motor neurons (Elde et al., 1991). The present study characterizes the cellular distribution of aFGF in the adult rat CNS by a combination of immunohistochemical and bioassay methods, and demonstrates a significant overlap of the distribution of aFGF with that of the low-affinity NGF receptor (LNGFR).

\section{Materials and Methods}

Generation and characterization of an antiserum to aFGF. Recombinant human aFGF was expressed in Escherichia coli as described previously (Imamura et al., 1990). The expression vector used was a generous gift of Dr. T. Maciag (American Red Cross). Bacteria expressing aFGF (21 gm wet weight) were collected by centrifugation $(10,000 \times g$ for $10 \mathrm{~min})$, frozen, thawed, and homogenized in $420 \mathrm{ml}$ of $20 \mathrm{~mm}$ Tris, $5 \mathrm{~mm}$ EDTA, $10 \mathrm{~mm}$ mercaptoethanol, $\mathrm{pH} \mathrm{8.0}$. All subsequent purification steps were carried out at $4^{\circ} \mathrm{C}$. The homogenate was centrifuged for $10 \mathrm{~min}$ at 20,000 $\times g$, and the resulting supernatant was made $300 \mathrm{~mm}$ in $\mathrm{NaCl}$ by the addition of $3 \mathrm{M} \mathrm{NaCl}$, and applied onto a $50 \mathrm{ml}$ heparin Affigel (BioRad) column. The column was washed with $150 \mathrm{ml}$ of homogenization buffer containing $650 \mathrm{mM} \mathrm{NaCl}$ and eluted with $150 \mathrm{ml}$ of homogenization buffer containing $1.5 \mathrm{M} \mathrm{NaCl}$. Fractions of the eluate that showed greater than 0.05 optical density units at $280 \mathrm{~nm}$ were combined, diluted fivefold with $\mathrm{H}_{2} \mathrm{O}$, and applied onto a $5 \mathrm{ml}$ heparin Econo-cartridge (Bio-Rad). The cartridge was washed with $20 \mathrm{ml}$ of homogenization buffer containing $750 \mathrm{mM} \mathrm{NaCl}$ and eluted with a linear gradient from $750 \mathrm{~mm}$ to $1.5 \mathrm{M} \mathrm{NaCl}$ in $20 \mathrm{~mm}$ sodium phosphate, $\mathrm{pH} 7.0(200 \mathrm{ml}$ total gradient volume). Fractions containing high levels of aFGF bioactivity (determined by the bioassay described below) were collected, and the purity of the fractions was analyzed by polyacrylamide gel electrophoresis in the presence of SDS. A single $16 \mathrm{kDa}$ protein species, the characteristic molecular mass of aFGF, was detected in these fractions. Approximately $250 \mathrm{mg}$ of aFGF was isolated from $21 \mathrm{gm}$ of bacteria. The purified protein was fully active at less than $1 \mathrm{ng} / \mathrm{ml}$ in the bioassay described below. The presence of heparin in the assay was required for the biological activity of the recombinant protein, demonstrating that the purified recombinant protein had the biological characteristics typical for aFGF.

Antigen for immunization of rabbits was prepared from this purified aFGF as follows. aFGF $(9 \mathrm{mg})$ was reacted for $1 \mathrm{hr}$ on ice with $10 \mu \mathrm{l}$ of a $25 \%$ glutaraldehyde solution (Sigma). The reaction was stopped by the addition of $1 \mathrm{ml}$ of $200 \mathrm{~mm}$ Tris, $\mathrm{pH} 8.0$. After $30 \mathrm{~min}$, another 9 $\mathrm{mg}$ of aFGF were added to the glutaraldehyde-treated aFGF, resulting in an antigen mixture that contained both lightly cross-linked and native aFGF. Antisera were prepared in two female young adult New Zealand albino rabbits by subcutaneous injection of this antigen. The injections (spaced at 6 week intervals) consisted of $750 \mu \mathrm{g}$ of antigen emulsified either in Freund's complete adjuvant (first injection), or in Freund's incomplete adjuvant (following three injections). Sera were collected after the fourth injection.

Twenty microliter aliquots of the sera were diluted with $400 \mu \mathrm{l}$ of 100

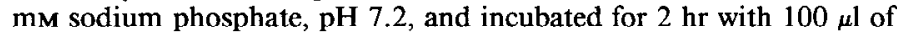
Affigel-10 (Bio-Rad) to which either $80 \mu \mathrm{g}$ of aFGF or $80 \mu \mathrm{g}$ of bFGF (a gift from Dr. C. Hart, Zymogenetics) had been coupled (as specified by the manufacturer's instructions). The FGF-Affigel was removed by centrifugation $(15,000 \times g$ for $3 \mathrm{~min})$, and the resulting supernatants (adsorbed sera) were collected.

The binding of antibodies in nonadsorbed and adsorbed sera to aFGF and $\mathrm{bFGF}$ was quantified as follows. Wells of 96-well microtiter plates (Corning) were coated with either $100 \mathrm{ng} /$ well of bFGF (Zymogenetics) or $100 \mathrm{ng} /$ well of aFGF (purified human recombinant $\mathrm{aFGF}$ ) and allowed to sit overnight at $4^{\circ} \mathrm{C}$. Wells were washed, and blocking solution [ $20 \%$ horse serum, $0.2 \%$ sodium azide in PBS (10 mM sodium phosphate, $150 \mathrm{~mm} \mathrm{NaCl}, \mathrm{pH} 7.0$ )] was added. After $5 \mathrm{hr}$ the blocking solution was removed and replaced with one of the following antisera: (1) rabbit anti-aFGF, (2) aFGF-adsorbed rabbit anti-aFGF, (3) bFGFadsorbed rabbit anti-aFGF, (4) normal rabbit serum, diluted in blocking solution. Antisera were tested in twofold serial dilutions (ranging from $1: 250$ to $1: 64,000$ ). Plates were incubated in antisera overnight at $4^{\circ} \mathrm{C}$. The next day the antisera were removed, and the wells were washed three times with PBS containing 0.05\% Tween. Wells were then incubated for $60 \mathrm{~min}$ in secondary antibodies [goat anti-rabbit coupled to alkaline phosphatase (Promega), 1:500 in PBS containing 10\% horse serum], washed three times with PBS containing $0.05 \%$ Tween and once with phosphatase buffer ( $100 \mathrm{~mm}$ Tris, $100 \mathrm{~mm} \mathrm{NaCl}, 5 \mathrm{mM} \mathrm{MgCl}_{2}, \mathrm{pH}$ 9.5), and reacted for $60 \mathrm{~min}$ with $1 \mathrm{mg} / \mathrm{ml}$ para-nitrophenyl phosphate (Sigma) in phosphatase buffer. The reaction was quantified by measurement of the optical density at $405 \mathrm{~nm}$.

Immunohistochemistry. Adult female Long-Evans rats were anesthetized and perfused through the heart with $50 \mathrm{ml}$ of $100 \mathrm{~mm}$ sodium phosphate, $\mathrm{pH} 7.2$, followed by $300 \mathrm{ml}$ of $10 \%(\mathrm{v} / \mathrm{v})$ formalin in the same buffer. Tissues were dissected, postfixed in $10 \%$ buffered formalin for $1 \mathrm{hr}$ at room temperature, and then equilibrated in $30 \%$ sucrose in $100 \mathrm{~mm}$ sodium phosphate, $\mathrm{pH} 7.2$. Serial $50-\mu \mathrm{m}$-thick frozen coronal sections extending from the olfactory bulb to the cervical spinal cord were cut. Groups of five sequential sections were collected into individual wells, thereby allowing staining for different antigens in sections originating from the same well that were separated by no more than $150 \mu \mathrm{m}$

For immunohistochemical staining, sections were first incubated for $2 \mathrm{hr}$ in $100 \mathrm{~mm}$ Tris, $150 \mathrm{~mm} \mathrm{NaCl}, 0.5 \%$ Triton X-100, 10\% horse serum, $0.05 \%$ sodium azide, $\mathrm{pH} 7.8$ (buffer $\mathrm{A}$ ), followed by overnight incubation in one of the following primary antibodies diluted in buffer $\mathrm{A}$ mouse monoclonal anti-LNGFK (Boehringer; $4 \mu \mathrm{g} / \mathrm{ml}$ ); mouse control ascites (Sigma; diluted 1:2000); rabbit anti-aFGF, rabbit anti-aFGF (adsorbed with bFGF), rabbit anti-aFGF (adsorbed with aFGF), and rabbit nonimmune serum (all rabbit sera were diluted 1:2000). Sections were then washed and incubated for $1 \mathrm{hr}$ in either anti-mouse or antirabbit secondary antibodjes (Sternberger-Meyer; diluted 1:100 in buffer A containing 5\% rat serum), washed, incubated for $1 \mathrm{hr}$ in either mouse or rabbit peroxidase-antiperoxidase complex (Sternberger-Meyer; diluted 1:100 in buffer A containing no sodium azide, but containing 5\% rat serum), washed, and reacted for $10 \mathrm{~min}$ with diaminobenzidine (1 $\mathrm{mg} / \mathrm{ml}$ ) and $0.03 \%$ hydrogen peroxide in PBS. Some of the stained sections were counterstained with thionin. The stained sections were mounted and coverslipped according to standard procedures.

For anatomical analysis, a frequently used stereotaxic atlas of the rat CNS (Paxinos and Watson, 1986) was employed to determine the precise location of stained neurons. The size of stained neurons was estimated by comparison with serial $10 \mu \mathrm{m}$ gradations on a stage micrometer. Neuronal cell bodies were classified as either small $(<12 \mu \mathrm{m}$ in diameter), medium (between $12 \mu \mathrm{m}$ and $20 \mu \mathrm{m}$ diameter), or large ( $>20 \mu \mathrm{m}$ diameter). The relative abundance of stained neurons in a given area was estimated in thionin-counterstained material, and the intensity of staining was evaluated according to subjective standards.

Determination of heparin-dependent mitogenic activity in tissue extracts. Adult female Long-Evans rats were killed by asphyxiation with carbon dioxide, and tissues were dissected, frozen immediately, and stored at $-70^{\circ} \mathrm{C}$ for no longer than $14 \mathrm{~d}$. Tissues were thawed and quickly homogenized in $10 \mathrm{ml} / \mathrm{gm}$ of ice-cold $20 \mathrm{~mm}$ Tris, $\mathrm{pH} 8.2$, containing $600 \mathrm{~mm} \mathrm{NaCl}$. The homogenates were centrifuged for 10 min at $15,000 \times g$, supernatants were collected, and protein concentration in supernatants was determined using a Coomassie blue binding assay (Bio-Rad). Extracts from at least three different animals were assayed for all data presented in this study.

The total amount of mitogenic activity present in tissue and cell culture extracts was determined using a serum-free ${ }^{3} \mathrm{H}$-thymidine incorporation assay as described earlier (Shipley, 1986; Eckenstein et al., 1991a). Briefly, AKR-2B cells were grown to confluence in 24 well culture plates. The cells were incubated for an additional $2 \mathrm{~d}$ in serumfree MCDB 402 medium (Shipley and Ham, 1981). Fresh MCDB 402, supplemented with varying concentrations of aFGF, $\mathrm{bFGF}$, or tissue extracts, was then added, and $22 \mathrm{hr}$ later the cultures were pulsed with $1.0 \mu \mathrm{Ci}$ of ${ }^{3} \mathrm{H}$-thymidine for $1 \mathrm{hr}$. The relative incorporation of ${ }^{3} \mathrm{H}$ thymidine into cold $10 \%$ trichloroacetic acid-insoluble material was then measured. Total mitogenic activity in extracts was determined from dose-response curves for the extracts. One unit of mitogenic activity was defined as the amount that yields half-maximal stimulation per milliliter of assay medium.

In this assay, aFGF is only active in the presence of heparin, whereas bFGF is active also in the absence of heparin. Thus, dose-response curves were determined with and without heparin $(1 \mu \mathrm{g} / \mathrm{ml}$; Sigma). The ratio of extract activity measured in the presence and absence was then used to estimate the level of aFGF in the extracts as described earlier in detail (Eckenstein et al., 1991b). 
A

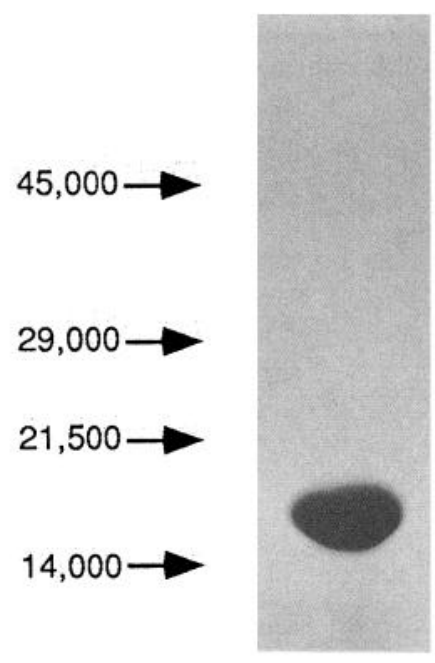

B O.D.

$405 \mathrm{~nm}$

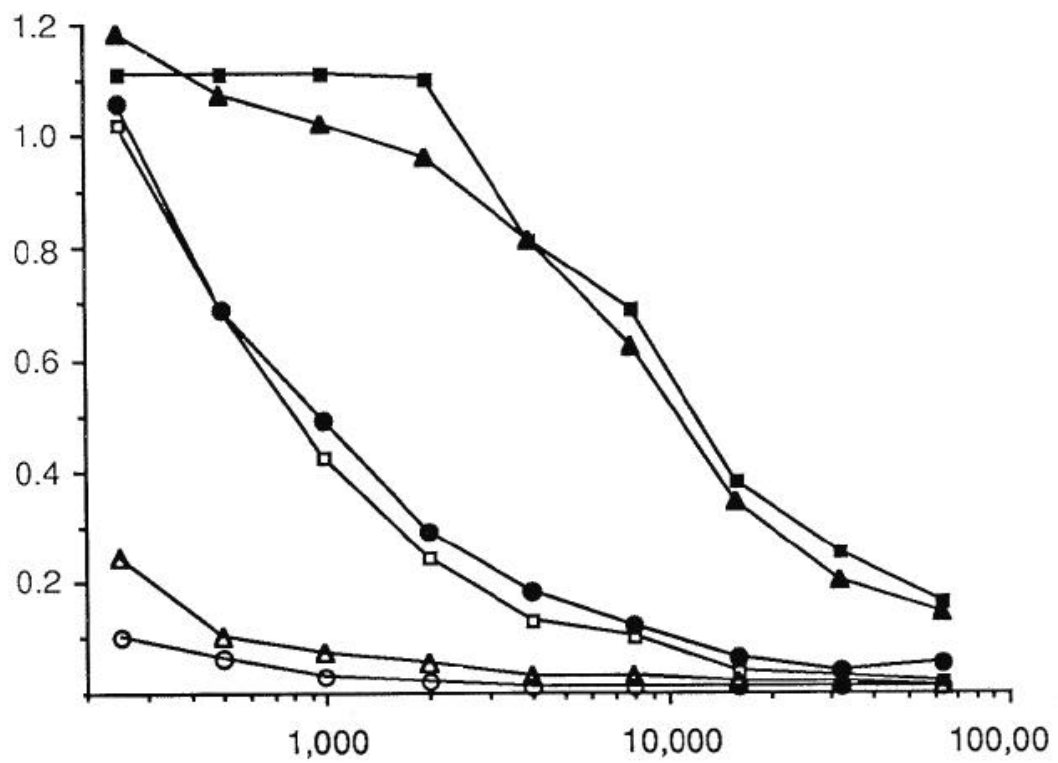

Antiserum dilution

Figure 1. Characterization of recombinant aFGF and of antiserum to aFGF. $A$, Twenty micrograms of purified recombinant aFGF were analyzed by polyacrylamide gel electrophoresis in the presence of SDS (see Materials and Methods for details). A single protein band of an apparent molecular mass of $16,000 \mathrm{Da}$ is present in the purified preparation. $B$. Antisera prepared against the purified recombinant aFGF were analyzed by ELISA for their binding to aFGF and bFGF. Nonadsorbed antiserum, antiserum adsorbed with bFGF, and antiserum adsorbed with aFGF were tested

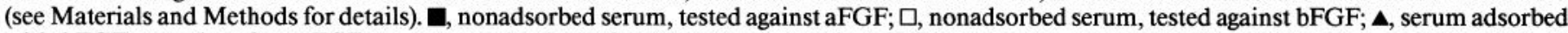
with $\mathrm{bFGF}$, tested against $\mathrm{aFGF} ; \triangle$, serum adsorbed with bFGF, tested against bFGF; $\bullet$, serum adsorbed with aFGF, tested against aFGF; 0 , serum adsorbed with aFGF, tested against bFGF. Note that the nonadsorbed antiserum preferentially binds to aFGF, but shows some crossreactivity with bFGF. Preadsorption with bFGF abolishes this cross-reactivity, and preadsorption with aFGF dramatically reduces binding to both aFGF and bFGF.
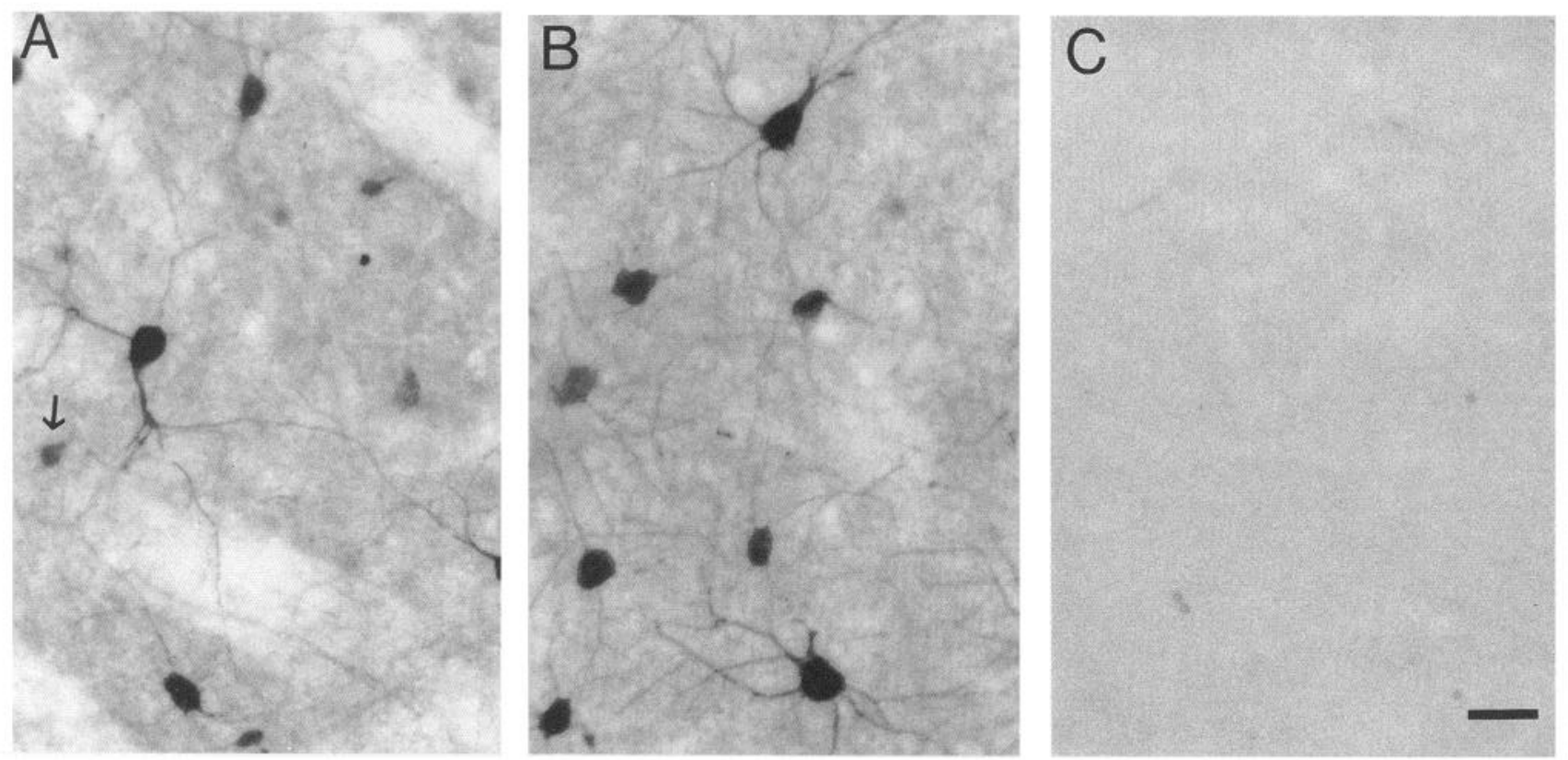

Figure 2. Immunohistochemical characterization of nonadsorbed and preadsorbed anti-aFGF serum. An immunoperoxidase method (see Materials and Methods for details) was used to analyze the immunohistochemical staining patterns produced by nonadsorbed $(A)$, bFGF-adsorbed $(B)$, and aFGF-adsorbed $(C)$ sera on sections through the rat CNS. Shown are sections through the caudate nucleus. The nonadsorbed serum and the bFGFadsorbed serum label neuronal populations of similar abundance and morphology, whereas no staining is observed using aFGF-adsorbed serum. Both large, strongly stained neurons, and smaller, weakly stained neurons (arrow in $A$ ) are observed. Note that the staining in labeled cells is present throughout the cell body without noticeable absence of staining in the area of the cell nucleus. Scale bar, $32 \mu \mathrm{m}$. 

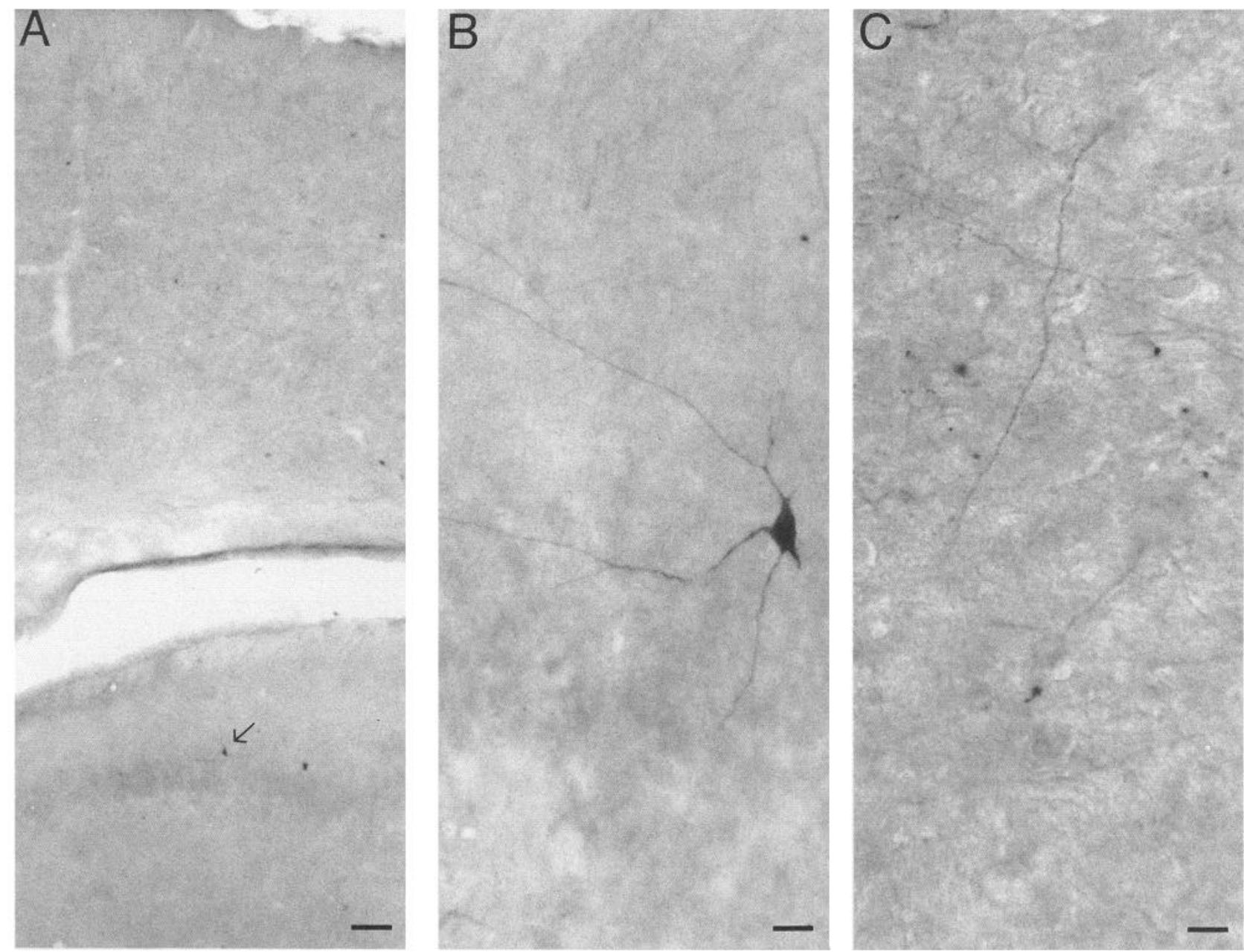

Figure 3. Immunohistochemical localization of aFGF immunoreactivity in cerebral cortex and hippocampus. $A$ shows a low-power photomicrograph of a coronal section spanning all of cerebral cortex and most of hippocampus. Few aFGF-positive neurons are observed in these areas. The cell identified by an arrow in $A$ is shown at larger magnification in $B$. The irregular multipolar morphology of this cell is representative for the morphology of most aFGF-positive cortical and hippocampal neurons. Fibers containing aFGF immunoreactivity in cingulate cortex are shown in $C$. The density of labeled fibers appears to be too high for fibers that would originate solely from the few aFGF-positive neurons within cortex. Scale bars: $A, 120 \mu \mathrm{m} ; B, 15 \mu \mathrm{m} ; C, 8 \mu \mathrm{m}$.

\section{Results}

Preparation and characterization of an antiserum to aFGF

Recombinant aFGF was expressed in E. coli and purified by heparin affinity chromatography (see Materials and Methods for details). The resulting purified material migrated as a single band with an apparent molecular weight of $16,000 \mathrm{Da}$ in SDS-gel electrophoresis (Fig. 1A) and exhibited maximal stimulation of DNA synthesis in a fibroblast cell line at concentrations of about $1 \mathrm{ng} / \mathrm{ml}$ (not shown), a level of activity indistinguishable from native human aFGF.

Antisera against this purified aFGF preparation were raised in rabbits. Because aFGF and bFGF share significant amino acid sequence identity, the cross-reactivity of the anti-aFGF serum to bFGF was determined by an enzyme-linked immunoassay, measuring the dilution of the antisera that showed halfmaximal binding (from here on referred to as $\mathrm{ED}_{50}$ ) to wells coated with either $1 \mathrm{ng}$ of aFGF or $1 \mathrm{ng}$ of bFGF (Fig. $1 B$ ). The antiserum used for the present study had an $\mathrm{ED}_{50}$ of 1:12,000 when tested against aFGF, and of 1:850 against bFGF, showing $7.1 \%$ cross-reactivity to bFGF. After adsorption with excess
bFGF, the same antiserum had an $\mathrm{ED}_{50}$ of $1: 10,000$ against $\mathrm{aFGF}$, and of less than 1:100 against bFGF, showing less than $1 \%$ cross-reactivity. Adsorption of the antiserum with excess aFGF lowered the $\mathrm{ED}_{50}$ to 1:1000 against aFGF, and below the limit of detection against bFGF.

A peroxidase-antiperoxidase immunohistochemical technique was used to investigate the specificity of the pattern of staining produced by the nonadsorbed and adsorbed antiserum. In representative sections throughout rat CNS, it was found that the nonadsorbed and bFGF-adsorbed antisera stained identical specific populations of neuronal cell bodies and processes, whereas the aFGF-adsorbed antiserum did not stain any structures (Fig. 2). All structures described below as aFGF positive were found to be labeled equally well by the nonadsorbed and the bFGF-adsorbed antisera.

\section{Immunohistochemical analysis of aFGF distribution in the rat $C N S$}

The distribution of aFGF immunoreactivity was determined in coronal sections throughout the rat CNS. Evaluation of the location, size, abundance, and intensity of staining of neuronal 
Table 1. Distribution of aFGF-positive neurons

\begin{tabular}{|c|c|c|c|}
\hline Location & $\begin{array}{l}\text { Abundance of } \\
\text { stained neurons } \\
+=\text { some } \\
++=\text { substantial } \\
+++=\text { most }\end{array}$ & $\begin{array}{l}\text { Size of } \\
\text { stained neurons } \\
+=\text { small } \\
++=\text { medium } \\
+++=\text { large }\end{array}$ & $\begin{array}{l}\text { Intensity of } \\
\text { staining } \\
+=\text { weak } \\
++=\text { moderate } \\
+++=\text { strong }\end{array}$ \\
\hline \multicolumn{4}{|l|}{ Areas of cerebral cortex } \\
\hline Frontal cerebral cortex & + & + & + and ++ \\
\hline Claustrum & ++ & + and ++ & + and ++ \\
\hline \multicolumn{4}{|l|}{ Subcortical telencephalon } \\
\hline Caudate & + & + and +++ & + and +++ \\
\hline Globus pallidus & ++ & ++ & ++ \\
\hline Ventral pallidum & + & ++ & ++ \\
\hline Lateral septal nuclei & ++ & + and ++ & + and ++ \\
\hline Diagonal band of Broca & ++ & ++ & ++ \\
\hline Nucleus basalis & +++ & ++ & ++ \\
\hline \multicolumn{4}{|l|}{ Thalamus } \\
\hline Paraventricular nucleus, anterior & +++ & + and ++ & + \\
\hline Mediodorsal nucleus & ++ & ++ & + \\
\hline Anterodorsal nucleus & +++ & ++ & ++ \\
\hline Lateral dorsal nuclei & ++ & + and ++ & + and ++ \\
\hline Central medial nucleus & ++ & ++ & + \\
\hline Lateral posterior medial nuclei & + and ++ & + and ++ & + and ++ \\
\hline Ventral lateral geniculate & ++ and +++ & + and ++ & ++ \\
\hline \multicolumn{4}{|l|}{ Hypothalamus } \\
\hline Anterior commissural nucleus & ++ & ++ & ++ and +++ \\
\hline I ateroanterior nucleus & +++ & ++ & ++ \\
\hline Medial preoptic area & ++ & ++ & ++ \\
\hline Lateral hypothalamic area & + & + and ++ & + and ++ \\
\hline Zona incerta & ++ & ++ & ++ \\
\hline Substantia innominata & + & + and ++ & + and ++ \\
\hline \multicolumn{4}{|l|}{ Midbrain } \\
\hline Substantia nigra & ++ & ++ & ++ \\
\hline Anterior pretectal nucleus & ++ & + and ++ & + and ++ \\
\hline Red nucleus & +++ & +++ & ++ \\
\hline Dorsal central gray & +++ & + and ++ & + and ++ \\
\hline Central gray & + & + and ++ & + and $t+$ \\
\hline Superior colliculus & + & + and +++ & + and ++ \\
\hline Inferior colliculus & + & + and +++ & + and ++ \\
\hline $\begin{array}{l}\text { Nucleus of the brachium of } \\
\text { the inferior colliculus }\end{array}$ & + & ++ & ++ \\
\hline Subbrachial nucleus & + & ++ & ++ \\
\hline Motor nucleus 3 & +++ & +++ & ++ and +++ \\
\hline Sensory, mesencephalic 5 & $+t+$ & +++ & +++ \\
\hline \multicolumn{4}{|l|}{ Brainstem and cerebellum } \\
\hline All deep cerebellar nuclei & ++ & + and ++ & ++ \\
\hline Pontine tegmentum & + & + and +++ & + and +++ \\
\hline Pontine nuclei & + and ++ & + & + and ++ \\
\hline Central gray & + & + and ++ & + and ++ \\
\hline Reticular nuclei & ++ & ++ and +++ & ++ and +++ \\
\hline Raphe nuclei & ++ and +++ & ++ and +++ & ++ and +++ \\
\hline Cochlear nuclei & +++ & + and ++ & ++ \\
\hline Medial and spinal vestibular nuclei & ++ & + and ++ & ++ \\
\hline Lateral vestibular nucleus & ++ & +++ & ++ \\
\hline Trapezoid body & +++ & + & + \\
\hline All motor nuclei & +++ & +++ & ++ and +++ \\
\hline Sensory, mesencephalic 5 & +++ & $1+t$ & $1+1$ \\
\hline
\end{tabular}



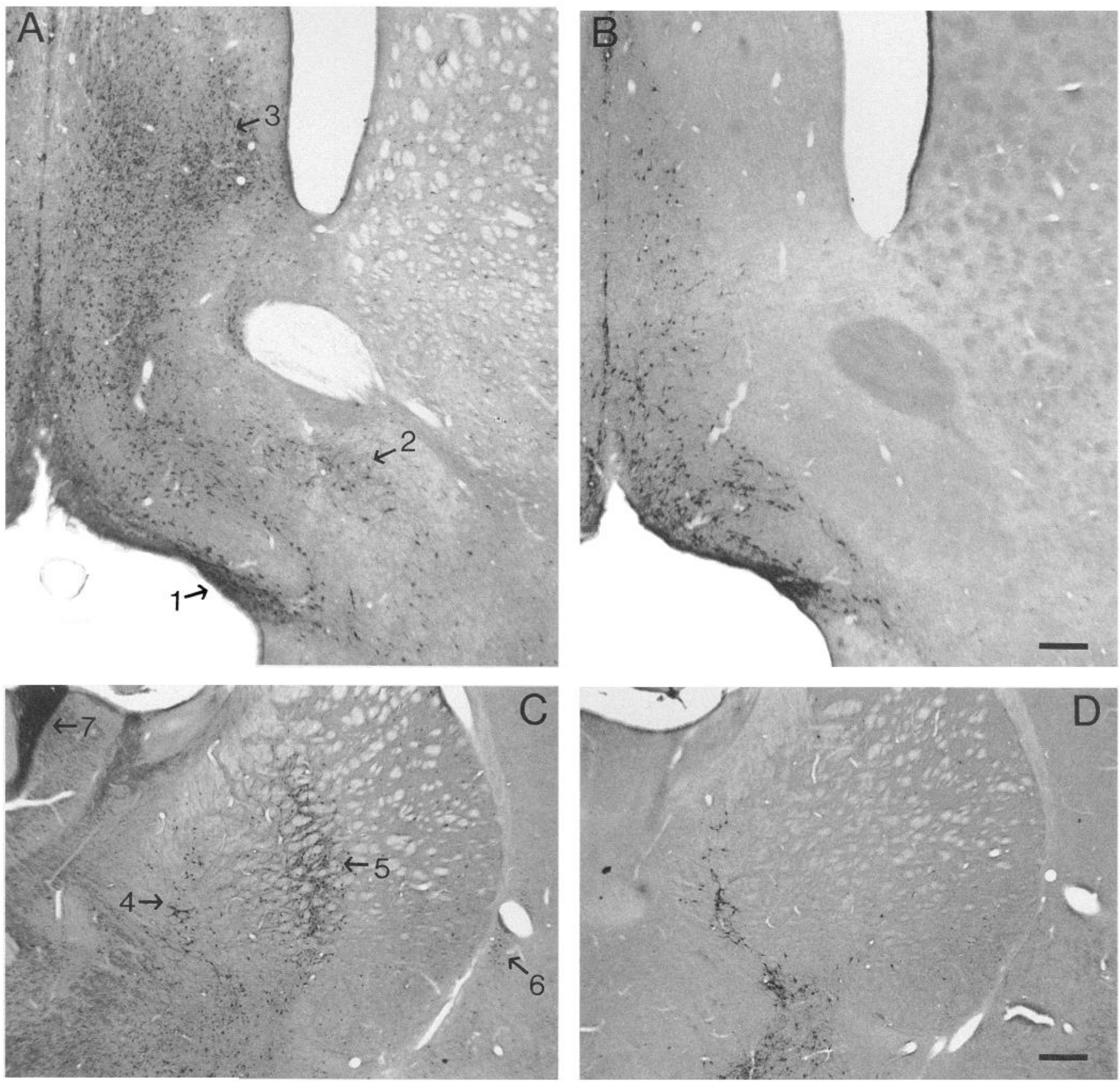

Figure 4. Immunohistochemical localization of aFGF and LNGFR immunoreactivity in the forebrain. Within the septal area, aFGF-immunoreactive neurons $(A)$ are found within the diagonal band of Broca $(I)$, the ventral pallidum (2), and the lateral septal nuclei (3), but LNGFRimmunoreactive neurons $(B)$ are present in the diagonal band only. In more caudal areas of the forebrain, numerous aFGF-immunoreactive neurons $(C)$ are present within the nucleus basalis (4), the globus pallidus (5), the claustrum (6), and the anterodorsal thalamic nucleus, but LNGFRimmunoreactive neurons $(D)$ are present in only the nucleus basalis. Scale bars: $A$ and $B, 220 \mu \mathrm{m} ; C$ and $D, 400 \mu \mathrm{m}$.

cell bodies (see Materials and Methods for details) allowed a good overall classification of staining (Table 1). In general, the distribution of immunoreactivity within neurons appeared to be predominantly cytoplasmic, although it was often somewhat granular in appearance. Dendritic and axonal processes, as well as perikarya of labeled cells, were clearly stained. In many labeled neuronal populations, such as in neurons in the red nucleus (see Fig. 6B), no aFGF immunoreactivity was detected in the nucleus. In other labeled populations, such as in aFGF-positive neurons in the caudate (Fig. 2), immunoreactivity appeared to be present throughout the cells, probably including the nucleus.
Clearly, the subcellular distribution of aFGF in neurons will have to be further investigated using higher-resolution techniques.

In more detail, the cerebral cortex and hippocampus contained only a very few stained neuronal cell bodies (Fig. 3), with the claustrum being the only cortical area that showed a moderately high density of stained neurons. Most stained cortical and hippocampal neurons had a multipolar appearance and were of small to medium size. In most cortical areas they were more abundant in layers 5 and 6 than in more superficial layers. Staining of neuronal processes was also observed in both hip- 

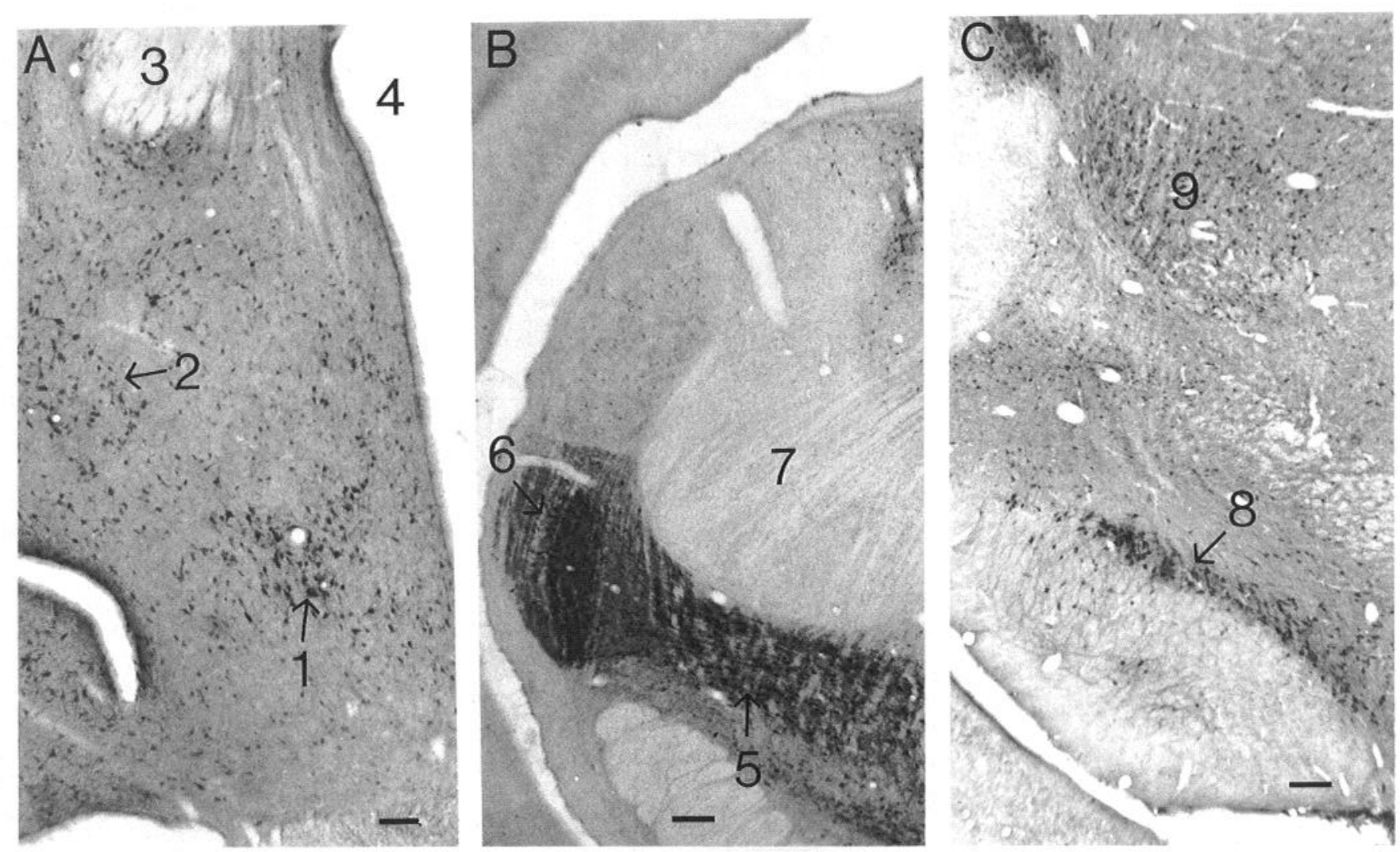

Figure 5. Immunohistochemical localization of aFGF-immunoreactive neurons in coronal sections through hypothalamus, thalamus, and the midbrain. Diffuse distribution of aFGF-immunoreactive neurons is observed in most of hypothalamus $(A)$, with labeled neurons being more numerous in the medial preoptic area ( 1 ) and in aspects of the lateral hypothalamic area (2). The fornix (3) and the third ventricle (4) are marked for orientation in $A$. Abundant labeled neurons are also present in the zona incerta $(B, 5)$. In thalamus, labeled neurons are abundant in the ventral LGN (6), but only few labeled neurons are seen in the directly overlying dorsal LGN. No labeled neurons are seen in the somatosensory relay nuclei, such as the ventral posteromedial nucleus (7). In midbrain $(C)$, aFGF immunoreactivity is observed in neurons in the substantia nigra (8) and the anterior pretectal nucleus (9). Scale bars: $A, 100 \mu \mathrm{m} ; B, 180 \mu \mathrm{m} ; C, 160 \mu \mathrm{m}$.

pocampus and cortex (Fig. 3). The density of stained processes in most cortical areas suggested that they originated from neurons located in subcortical areas (such as the basal forebrain LNGFR-positive neurons; see below) and were not due solely to the few cortical aFGF-positive neurons.

In subcortical telencephalic areas, aFGF immunoreactivity was most noticeable in a small number of defined neuronal populations, including neurons in the diagonal band of Broca, the globus pallidus, the ventral pallidum, the caudate, and the nucleus basalis (Fig. 4). Most of the stained neurons were of medium to large size and had a multipolar morphology. In some areas, more than one population of neurons appeared to be stained. This was most noticeable in the caudate where a population of medium to large neurons was strongly stained whereas a population of small neurons was weakly stained (Fig. 2). Neither of these populations represented more than $10 \%$ of all neurons in the caudate. Strongly stained axons, possibly representing the cortical projection from the nucleus basalis, were found in fiber bundles within the caudate. Very weakly stained fibers seen in cellular areas of the caudate may be due to the presence of aFGF-positive intrinsic neurons or may represent aFGF-positive terminals of nigrostriatal neurons (see below).

Specific populations of aFGF-positive neurons were observed in a number of nuclei in the thalamus. The morphology and staining intensity of the labeled populations varied considerably, and any given stained population appeared to be confined to a single thalamic nucleus. This resulted in a very characteristic overall staining pattern in thalamus. For example, the nuclei proper of the ventral division of the thalamus (with the exception of the ventral lateral geniculate) were completely devoid of aFGF immunoreactivity, whereas neighboring nuclei contained well-stained neurons, resulting in a characteristic staining pattern outlining the ventral nuclei (Fig. $5 B$ ). Weakly stained axons were observed in the optic radiation and in the dorsal LGN.

A diffuse distribution of numerous aFGF-positive neurons of varying morphology was observed in hypothalamus and associated areas (Fig. 5A). The highest density of stained neurons was found in medial preoptic and lateral hypothalamic areas. Paraventricular and supraoptic nuclei did not contain a significant number of stained neurons. Weakly stained fibers were found throughout hypothalamus.

Most areas of the midbrain contained diffusely distributed aFGF-positive neurons of varying morphology. In addition, a large number of medium- to large-sized neurons were stained in all areas of the substantia nigra (Fig. 5C), the red nucleus (Fig. $6 B$ ), and the oculomotor nucleus (Fig. 6A). In addition, a large number of somewhat smaller neurons were stained in the dorsal central gray. Stained fibers were found in most areas of the midbrain, with the axons of oculomotor neurons and of sensory mesencephalic neurons being most noticeable.

All deep cerebellar nuclei contained numerous stained cell bodies, whereas no stained cell bodies were observed in cerebellar cortex. Sparse, weakly stained fibers were observed in all areas of the cerebellum. 

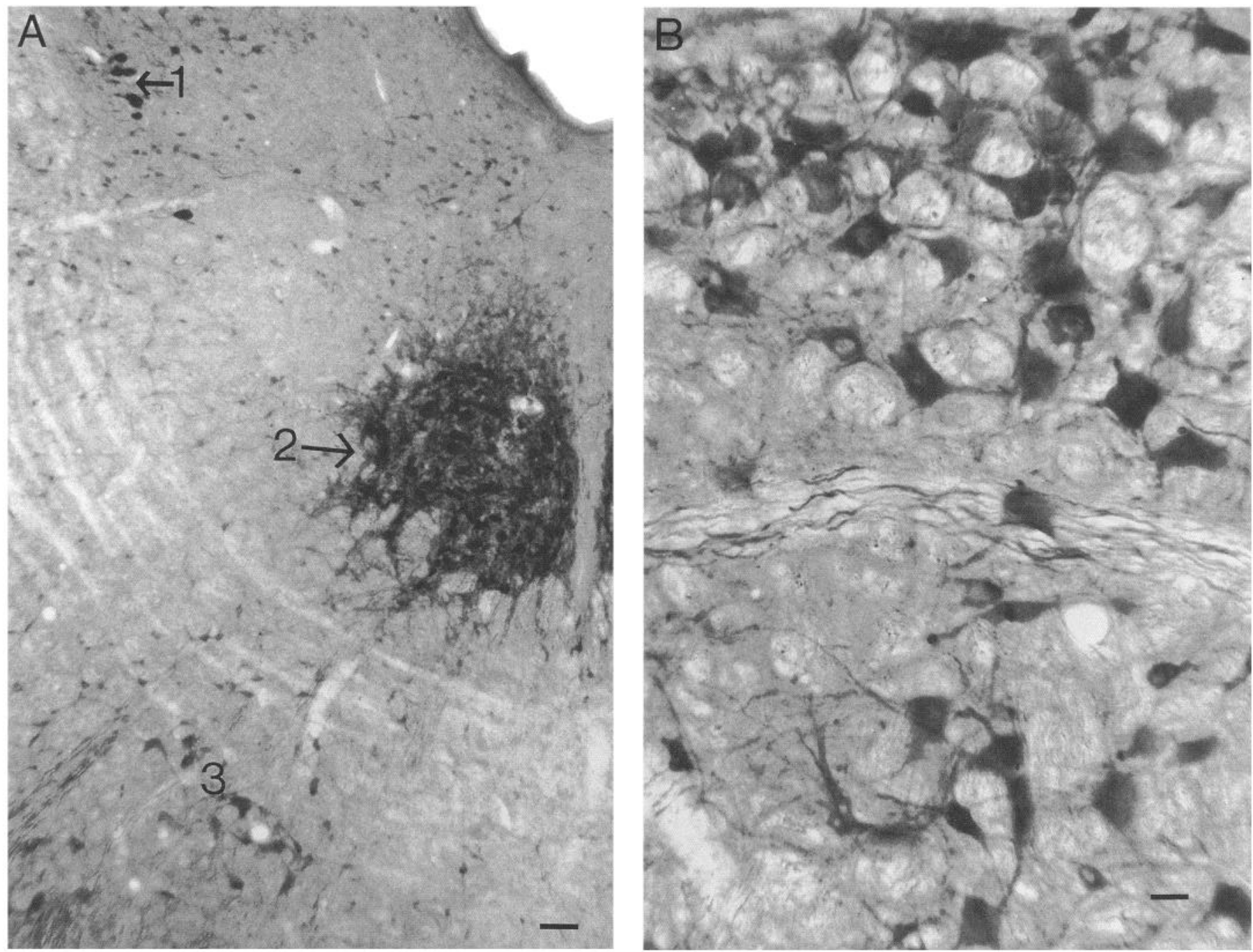

Figure 6. Immunohistochemical localization of aFGF in midbrain neurons. $A$ shows a low-power photomicrograph of a coronal section through the midbrain. Strong aFGF label is seen in mesencephalic sensory neurons (1), in oculomotor neurons (2), and in neurons of the red nucleus (3). Labeled motor neuron axons can be seen to course from the oculomotor nucleus toward and through the red nucleus. $B$ shows a higher-power photomicrograph of aFGF immunoreactivity in the red nucleus. Note that the aFGF staining of cell bodies of neurons in the red nucleus is predominantly cytoplasmic and spares the nucleus of labeled cells; also note the strong staining of oculomotor neuron axons running through the red nucleus. Scale bars: $A, 80 \mu \mathrm{m} ; B, 25 \mu \mathrm{m}$.

All motor and sensory neurons (Fig. 7) in the brainstem and spinal cord were strongly aFGF positive. In addition, large numbers of neurons in the reticular, raphe, cochlear, and vestibular nuclei were labeled. Distinct, strong staining of all sensory and motor axons and their fiber tracts (such as the spinal trigeminal tract) was also observed. Strongly stained terminals were most noticeable in areas innervated by primary sensory neurons, such as in the gracile nucleus (Fig. $7 A$ ).

\section{Overlap of aFGF and NGF receptor immunoreactivity}

The LNGFR is known to be expressed by neurons in the diagonal band of Broca, the nucleus basalis, and the mesencephalic trigeminal sensory nucleus (Eckenstein, 1988), areas that were found here to contain aFGF-positive neurons. The possibility that the distributions of aFGF immunoreactivity and of LNGFR expression overlap was investigated by staining of adjacent or nearby sections for either aFGF or LNGFR immunoreactivity (sections stained for the LNGFR were no farther than $200 \mu \mathrm{m}$ from those stained for aFGF). Results clearly demonstrated a considerable overlap between LNGFR expression and the presence of aFGF immunoreactivity (Figs. 4, 7).

\section{Distribution of aFGF bioactivity}

We had earlier shown that the levels of aFGF and bFGF in extracts prepared from nervous tissues could be determined using an in vitro bioassay method (Eckenstein et al., 1991b). This method relies on quantifying the stimulation of DNA synthesis induced in AKR-2B cells by the extracts. This assay can distinguish between bFGF and aFGF, as aFGF activity is strongly stimulated by heparin whereas bFGF activity is largely independent of heparin. Thus, the heparin dependence of mitogenic activity (defined as the amount of mitogenic activity observed in the presence of heparin divided by the amount of activity observed in the absence of heparin) can be used to calculate the relative contributions of aFGF and bFGF to the total activity present in an extract (Eckenstein et al., 1991b). 

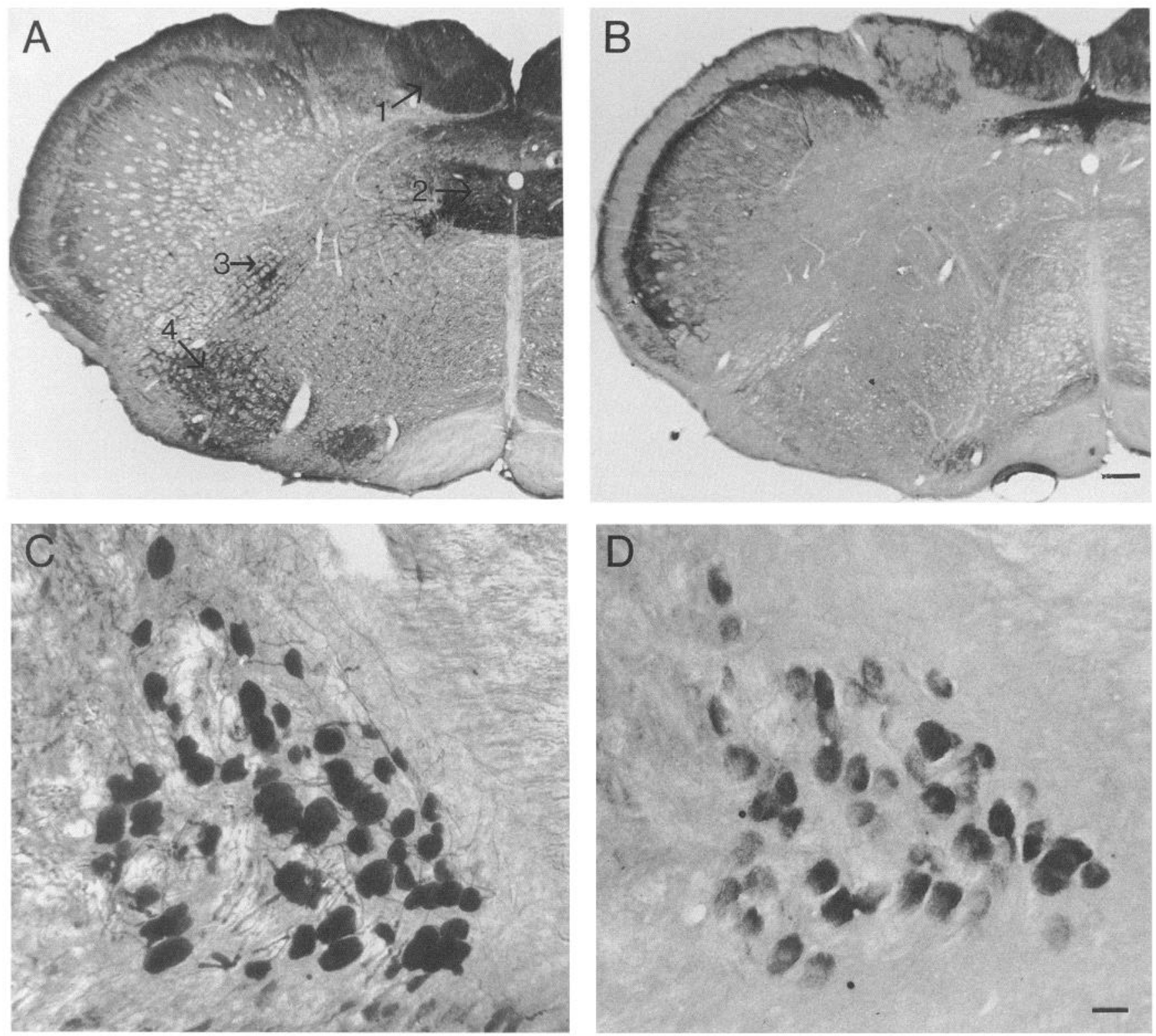

Figure 7. Immunohistochemical localization of aFGF and LNGFR immunoreactivity of the hindbrain. $A$ shows a low-power photomicrograph of the distribution of aFGF in a coronal section through the medulla oblongata. Dense, strongly labeled terminals are seen in the gracile nucleus (1), and in lesser densities in other areas innervated by primary sensory neurons. Strongly labeled aFGF-positive neurons are seen in motor neurons in the hypoglossal nucleus (2) and the nucleus ambiguus (3). Strongly labeled neurons are also seen in the lateral reticular nucleus (4). B illustrates the distribution of LNGFR immunoreactivity in a similar section. Note that LNGFR immunoreactivity is present in terminals in the gracile nucleus and additional areas innervated by primary sensory neurons. $C$ illustrates the strong aFGF staining of primary sensory neurons in the mesencephalic trigeminal nucleus. $D$ demonstrates the presence of LNGFR immunoreactivity in such sensory neurons in an adjacent section. Scale bars: $A$ and $B, 210 \mu \mathrm{m} ; C$ and $D, 25 \mu \mathrm{m}$.

For this study, the level of heparin-dependent aFGF bioactivity was determined in six areas of the rat nervous system (Table 2). Overall, the levels of aFGF bioactivity observed correlated well with the density of aFGF-positive structures detected by immunohistochemistry (Table 1). For example, aFGF levels were found to be very low in cerebral cortex and hippocampus, tissues that contained few aFGF-positive neurons, whereas spinal cord and sciatic nerve, which showed abundant aFGF-staining, also contained the highest levels of aFGF bioactivity.

\section{Discussion}

Anatomical analysis

The physiological role of FGFs in the CNS is not clear. As an initial step toward elucidating the role of these growth factors, the present study investigated the cellular distribution of aFGF in the CNS, using both immunohistochemical and bioassay methods. aFGF immunoreactivity was found to be present in very specific neuronal populations in the following areas of the CNS: (1) in subcortical telencephalon, where labeled popula- 
Table 2. Relative abundance of aFGF and bFGF in the nervous system

\begin{tabular}{lccccc} 
& \multicolumn{2}{c}{ Mitogenic units/mg } & & \\
\cline { 2 - 3 } Tissue & $\begin{array}{l}\text { With } \\
\text { heparin }\end{array}$ & $\begin{array}{l}\text { Without } \\
\text { heparin }\end{array}$ & & $\begin{array}{l}\text { Heparin } \\
\text { dependence }\end{array}$ & $\begin{array}{l}\text { Units of } \\
\text { aFGF/mg }\end{array}$ \\
\hline Cerebral cortex & 38 & 30 & & 1.3 & Not detectable \\
Subcortical telencephalon & 77 & 36 & 2.1 & 29 \\
Thalamus & 82 & 42 & 2.0 & 29 \\
Hypothalamus & 89 & 35 & 2.5 & 37 \\
Midbrain & 202 & 32 & 6.3 & 149 \\
Brainstem & 374 & 20 & 18.7 & 340 \\
Spinal cord & 493 & 26 & 18.7 & 449 \\
Sciatic nerve & 1301 & 12 & 108.4 & 1301 \\
\hline
\end{tabular}

SE of mitogenic activities was less than $15 \%$ of total.

tions included basal forebrain cholinergic neurons; (2) in certain specifically localized neuronal populations as well as in diffusely distributed neurons in the hypothalamus; (3) in certain neuronal populations in the thalamus, with a notable absence of staining in the specific sensory relay nuclei; (4) in many strongly labeled neuronal populations in midbrain, brainstem, and spinal cord, which include neurons of the substantia nigra, all motor neurons, and the mesencephalic trigeminal sensory neurons. Only a few isolated aFGF-positive neurons were found in the cerebral cortex and hippocampus, and cerebellar cortex was completely devoid of aFGF-positive cell bodies. Non-neuronal cells did not contain detectable levels of aFGF immunoreactivity.

The criteria used to evaluate the location, size, staining intensity, and density of aFGF-positive neuronal cell bodies (see Materials and Methods) allowed an initial characterization of the labeling observed (Table 1). This classification, however, does not identify the particular subpopulation of neurons stained in an area, nor does it address whether more than one population might be stained in any given area (e.g., see Fig. 2, reflecting the possible presence of two stained populations in the caudate). This limitation in our analysis points out that the results summarized in Table 1 represent a fair overview of the distribution of aFGF immunoreactivity within the rat CNS, but that a more precise identification of many of the neuronal cell types containing aFGF immunoreactivity will have to depend on more detailed anatomical analysis, using additional immunological markers for the identification of specific types of neurons.

As a first such more detailed analysis, we examined the possiblc overlap of aFGF-immunoreactive neurons with those staining for the LNGFR (see Radeke et al., 1987). This was of particular interest since several of the aFGF-positive neuronal populations identified here, such as motor, sensory, and basal forebrain cholinergic neurons, had been shown to express the LNGFR [either transiently during development or throughout adulthood (Eckenstein, 1988)]. Based on staining neighboring sections for LNGF or aFGF immunoreactivity, we observed substantial overlap in the distribution of the two antigens, suggesting that most of the LNGF-positive neurons may also contain aFGF. Double staining experiments, localizing these two antigens within a single section, will be necessary to determine whether this is indeed the case.

Interestingly, the family of trk proto-oncogenes has recently been shown to provide additional components of the NGF receptor system (Kaplan et al., 1991; Klein et al., 1991a,b; Soppet et al., 1991; Squinto et al., 1991). It is possible that $t r k$ receptors might be expressed more widely than the LNGFR. For example, the substantia nigra neurons appear to respond to brain-derived neurotrophic factor [a member of the NGF family (Hyman et al., 1991; Knüsel et al., 1991)], without expressing the LNGFR (Eckenstein, 1988). It will thus be of interest to determine whether there is additional overlap between $t r k$ and aFGF expression.

The specific immunohistochemical localization of any given member of the FGF family critically depends on the specificity of the antiserum used, and specifically that the antiserum does not recognize any additional family members. This is of special importance, as all members of the FGF family are structurally similar and share, within a core region, distinct amino acid sequence identity. Thus, the antiserum to aFGF used here was adsorbed with bFGF (the FGF family member most homologous to aFGF), and it was demonstrated that this preadsorption reduced to insignificant levels (less than 1\%) the slight crossreactivity of the aFGF antiserum with bFGF. This bFGF-adsorbed antiserum was found to stain the same neuronal populations as identified with the nonadsorbed antiserum. Adsorption of the antiserum with purified aFGF completely abolished all specific staining. Furthermore, we had shown earlier that bFGF is present predominantly in astrocytes and CA2 hippocampal neurons (Woodward et al., 1992), and not the neuronal populations shown here to contain aFGF immunoreactivity. Taken together, these data alone strongly suggest that the staining reported here reflects the specific distribution of aFGF.

As an alternative means for confirming this conclusion, we determined the levels of aFGF activity in dissected areas of rat CNS using a bioassay. In good agreement with the immunohistochemical pattern of staining described below, levels of aFGF activity were very low in cerebral cortex and cerebellar cortex, intermediate in the basal ganglia, and high in more caudal areas of the CNS. It should be noted here that the bioassay used is able to differentiate between bFGF and aFGF, as aFGF requires the presence of heparin in the assay in order to be active, whereas bFGF activity is largely independent of heparin (Eckenstein et al., 1991b). Although the bioassay is not completely specific for FGFs, we have shown earlier that the levels of aFGF estimated by the assay correlate well with the levels of aFGF estimated by Western blot techniques (Eckenstein et al., 1991a). Thus, only a molecule that is structurally more homologous to aFGF than bFGF, and that exhibits a heparin dependence of mitogenic activity similar to that of aFGF, could possibly interfere with 
the specificity of the methods used here. This possibility appears remote, as none of the known members of the FGF family possesses this unique combination of features.

The observations reported here are in good agreement with our earlier finding that peripheral axons and cultured sensory neurons contain very high levels of aFGF protein and bioactivity, whereas cerebral cortex and hippocampus contain ony very low levels (Eckenstein et al., 1991a,b). These results also agree with and expand on one recent report, which demonstrated the presence of aFGF and aFGF mRNA in sensory and motor neurons, but only in a negligible number of hippocampal and cortical neurons (Elde et al., 1991). Another study, however, employing in situ hybridization methods, reported a pattern of hybridization labeling most neurons, reminiscent of the pattern produced by standard Nissl stains (Wilcox and Unnerstall, 1991). This included strong hybridization of the aFGF antisense oligonucleotide to neurons in cerebral cortex, hippocampus, and cerebellar cortex. The reason for this discrepancy with the present and another study (Elde et al., 1991) is unclear, but it may be possible that the antisense oligonucleotide for the detection of aFGF mRNA cross-hybridized with other cellular mRNAs.

In addition, aFGF immunoreactivity has also been reported in ependymal cells lining the third ventricle (Tooyama et al., 1991). The antiserum to aFGF used in that study may have cross-reacted with bFGF, as we had shown earlier that these ependymal cells contain large amounts of bFGF (Woodward et al., 1992). Furthermore, bFGF immunoreactivity has also been reported to be present in neurons in sensory and motor areas of the brainstem (Grothe et al., 1991). Again, this observation may be due to cross-reactivity of the bFGF antibodies with aFGF, which is present in very high levels in these cells.

These apparent discrepancies clearly demonstrate the difficulties encountered when determining the distribution of specific, structurally similar members of a growth factor family. Thus, not only a careful and quantitative analysis of reactivity of antibodies or RNA probes to different members of the family is needed, but in addition, immunohistochemical localization of FGFs or in situ hybridization of FGF mRNAs should be confirmed by independent methods, such as bioassays or Northern or Western blots. It is noteworthy that studies employing such multiple techniques for characterizing the distribution of FGF family members generally agree well with each other and with the observations reported here (Eckenstein et al., 1991a; Elde et al., 1991; Woodward et al., 1992).

\section{Functional considerations}

The main problem for understanding the physiological role of FGFs within the CNS arises from observations that the different members of the FGF family appear to have overlapping mitogenic and neurotrophic activitites in in vitro bioassay systems (Burgess and Maciag, 1989; Eckenstein et al., 1990), and that $\mathrm{aFGF}$ and bFGF are both present in substantial amounts in the CNS. Our observation that aFGF and bFGF are present in completely different cell types suggests that the specific physiological role played by either of these factors is at least partially determined by its cellular localization.

Several recent reports have added clues as to what the functions of aFGF and bFGF might be. For example, aFGF and bFGF lack signal peptide sequences that are traditionally thought to be required for secretion (Walter and Lingappa, 1986); thus, these factors may not always be available in substantial quantities in the extracellular space. Indeed, we have not been able to detect substantial release of bFGF from cultured astrocytes (data not shown), which contain abundant intracellular and nuclear bFGF (Ferrara et al., 1988; Woodward et al., 1992). It is also known that bFGF is present in both the cytoplasm and the nucleus of cells expressing the factor (Baldin et al., 1990; Renko et al., 1990; Bugler et al., 1991; Woodward et al., 1992). This nuclear bFGF appears to be capable of stimulating the transcription of ribosomal RNAs (Amalric et al., 1991). A nuclear translocation sequence is also present in aFGF, and deletion of this sequence appears not to affect the binding to and activation of FGF receptors but abolishes the ability of aFGF to stimulate mitogenesis (Imamura et al., 1990). Interestingly, in the present light microscopic study we did not detect aFGF in the nuclei of most aFGF-positive neuronal populations, but a few populations, such as neurons in the caudate nucleus, showed aFGF staining throughout the cell, without sparing of the nucleus. Further studies, using electron microscopic techniques, will be necessary to determine the detailed intracellular distribution of aFGF.

It is at present unclear how and under which conditions aFGF and bFGF may be released from cells containing these factors, but it has been suggested that limited amounts of FGFs may bc released by unconventional mechanisms, such as by binding of FGF to intracellular heparan protenglycans, followed by appearance of the FGF-proteoglycan complex on the cell surface (Gordon et al., 1989; Vlodavsky et al., 1991). In addition, a recent study demonstrated that, although bFGF is not released from normal fibroblasts, it is released efficiently from highly transformed fibroblast cell lines (Kandel et al., 1991). Cell lysis may represent another possible mechanism for making large amounts of intracellular FGF available in the extracellular space. This might limit the extent of neuronal cell death after injury or during development, and may also promote the formation of non-neuronal scar tissue by stimulating mitogenesis of nonneuronal cells.

Additional evidence for an extracellular role for FGFs comes from the recent cloning and characterization of four different specific cell surface FGF reccptors (Bottaro et al., 1990; Dionne et al., 1990; Champion et al., 1991; Johnson et al., 1991; Keegan et al., 1991; Partanen et al., 1991). These receptors are transmembrane proteins, with the FGF binding site localized to the extracellular part of the receptor, and a tyrosine kinase motif localized to the intracellular part. Most of these receptors appear to bind aFGF and bFGF with similar affinity, but at least one of the receptors appears to bind only aFGF with high affinity (Miki et al., 1991). Widespread expression of one of the nonselective FGF receptors in the CNS has been reported (Heuer et al., 1990; Wanaka et al., 1990). In addition, it has become clear that cell surface heparan proteoglycans appear to be necessary for the binding of FGFs to their receptors (Rapraeger et al., 1991; Yayon et al., 1991), and these proteoglycans are likely to modulate the responses of cells to FGFs.

Taken together, these observations allow the formulation of the following hypothetical model for the function of FGFs in the nervous system. The model predicts that the specific functions of bFGF and of aFGF are separate, determined mainly by their differential cellular localization, but additional specificity may arise from the specific distribution of different receptors and heparan proteoglycans. Both intracellular and extracellular functions are predicted for both aFGF and bFGF. Intracellular functions of bFGF are expected to be limited to affecting the maturation and differentiation of astrocytes and 
CA2 hippocampal neurons, whereas extracellular bFGF is expected to mediate interactions of astrocytes and CA 2 neurons with cells in their vicinity.

Sufficient release is a prerequisite for the extracellular functions of aFGF, and it may be that damage and lysis of aFGFpositive neurons represent such a release mechanism. In this way, for example, aFGF may limit cell death during development of sensory neurons, because developing sensory neurons contain significant levels of aFGF (Eckenstein et al., 1991a; Schnürch and Risau, 1991) and express FGF receptors (Heuer et al., 1990), and their survival in vitro is promoted by aFGF (Eckenstein et al., 1990). It is thus possible that aFGF released from the first sensory neurons to die will transiently rescue neighboring neurons. These neurons thereby gain valuable time for establishing innervation of their target, resulting in access to amounts of NGF sufficient to maintain their long-term survival. The presence of significant amounts of aFGF in the mature nervous system indicates that such an action of aFGF may also be involved in promoting the maintenance of aFGF-containing neuronal populations. It is of particular interest in this respect that aFGF is localized in neurons known to be affected by degenerative diseases, such as basal forebrain cholinergic neurons (affected by Alzheimer's disease), neurons in the substantia nigra (affected by Parkinson's disease), and motor neurons (affected by amyotrophic lateral sclerosis). The reason for this correlation is unclear, but it may be hypothesized that neurons particularly susceptible to degeneration may express autoor paracrine trophic factors in order to minimize such susceptibility. The focus of the above hypothesis on auto- or paracrine mechanisms does not exclude the possibility that aFGF-positive neurons may provide aFGF to the targets they innervate (see, e.g., aFGF-positive basal forebrain afferents to cortex), nor does it exclude the possibility that aFGF may act as a trophic factor for neurons innervating the aFGF-positive cells.

In summary, our work on the distribution of FGFs in the nervous system has clearly established that aFGF and bFGF are present in completely different sets of cells, and thus are likely to have different biological functions. These observations, taken together with data reported by others, have allowed us to hypothesize about the nature of these multifaceted functions. Clearly, substantial experimental evidence will be needed to test the proposed model.

\section{References}

Amalric F, Baldin V, Bosc-Bierne I, Bugler B, Couderc B, Guyader M, Patry V, Prats H, Roman AM, Bouche G (1991) Nuclear translocation of basic fibroblast growth factor. Ann NY Acad Sci 638:127138.

Baldin V, Roman A, Bosc-Bierne I, Amalric F, Bouche G (1990) Translocation of bFGF to the nucleus is $\mathrm{Gl}$ phase cell cycle specific in bovine aortic endothelial cells. EMBO J 9:1511-1517.

Bottaro DP, Rubin JS, Ron D, Finch PW, Florio C, Aaronson SA (1990) Characterization of the receptor for keratinocyte growth factor. Evidence for multiple fibroblast growth factor receptors. J Biol Chem 265:12767-12770.

Bugler B, Amalric F, Prats H (1991) Alternative initiation of translation determines cytoplasmic or nuclear localization of basic fibroblast growth factor. Mol Cell Biol 11:573-577.

Burgess WH, Maciag T (1989) The heparin-binding (fibroblast) growth factor family of proteins. Annu Rev Biochem 58:575-606.

Champion AP, Ronsin C, Gilbert E, Gesnel MC, Houssaint E, Breathnach R (1991) Multiple mRNAs code for proteins related to the BEK fibroblast growth factor receptor. Oncogene 6:979-987.

Davis JB, Stroobant P (1990) Platelet-derived growth factors and fibroblast growth factors are mitogens for rat Schwann cells. J Cell Biol 110:1353-1360.
Dionne CA, Crumley G, Bellot F, Kaplow JM, Searfoss G, Ruta M, Burgess WH, Jaye M, Schlessinger J (1990) Cloning and expression of two distinct high-affinity receptors cross-reacting with acidic and basic fibroblast growth factor. EMBO J 9:2685-2692.

Eccleston PA, Silberberg DH (1985) Fibroblast growth factor is a mitogen for oligodendrocytes in vitro. Brain Res 353:315-318.

Eckenstein F (1988) Transient expression of NGF-receptor-like immunoreactivity in postnatal rat brain and spinal cord. Brain Res 446: 149-154.

Eckenstein FP, Esch F, Holbert T, Blacher RW, Nishi R (1990) Purification and characterization of a trophic factor for embryonic peripheral neurons: comparison with fibroblast growth factors. Neuron 4:623-631.

Eckenstein F, Woodward W, Nishi R (1991a) Differential localization and possible functions of aFGF and bFGF in the central and peripheral nervous system. Ann NY Acad Sci 638:348-360.

Eckenstein FP, Shipley GD, Nishi R (1991b) Acidic and basic fibroblast growth factors in the nervous system: distribution and differential alteration of levels after injury of central versus peripheral nerve. J Neurosci 11:412-419.

Elde R, Cao Y, Cintra A, Brelje TC, Pelto HM, Junttila T, Fuxe K, Pettersson RF, Hökfelt T (1991) Prominent expression of acidic fibroblast growth factor in motor and sensory neurons. Neuron 7 : 349-364.

Ferrara N, Ousley F, Gospodarowicz D (1988) Bovine brain astrocytes express basic fibroblast growth factor, a neurotropic and angiogenic mitogen. Brain Res 462:223-232.

Gordon PB, Choi HU, Conn G, Ahmed A, Ehrman B, Rosenberg L, Hatcher VB (1989) Extracellular matrix heparan sulfate proteoglycans modulate the mitogenic capacity of acidic fibroblast growth factor. J Cell Physiol 140:584-592.

Gospodarowicz D, Ferrara N, Schweigerer L, Neufeld G (1987) Structural characterization and biological functions of fibroblast growth factor. Endocrinol Rev 8:95-114.

Grothe C, Otto D, Unsicker K (1989) Basic fibroblast growth factor promotes in vitro survival and cholinergic development of rat septal neurons: comparison with the effects of nerve growth factor. Neuroscience 31:649-661.

Grothe C, Zachmann K, Unsicker K (1991) Basic FGF-like immunoreactivity in the developing and adult rat brainstem. J Comp Neurol 305:328-336.

Hatten ME, Lynch M, Rydel RE, Sanchez J, Joseph SJ, Moscatelli D, Rifkin DB (1988) In vitro neurite extension by granule neurons is dependent upon astroglial-derived fibroblast growth factor. Dev Biol $125: 280-289$.

Heuer JG, von Bartheld CS, Kinoshita Y, Evers PC, Bothwell M (1990) Alternating phases of FGF receptor and NGF receptor expression in the developing chicken nervous system. Neuron 5:283-296.

Hyman C, Hofer M, Barde YA, Juhasz M, Yancopoulos GD, Squinto SP, Lindsay RM (1991) BDNF is a neurotrophic factor for dopaminergic neurons of the substantia nigra. Nature 350:230-232.

Imamura T, Engleka K, Zhan X, Tokita Y, Forough R, Roeder D, Jackson A, Maier J, Hla T, Maciag T (1990) Recovery of mitogenic activity of a growth factor mutant with a nuclear translocation sequence. Science 249:1567-1570.

Johnson DE, Lu J, Chen H, Werner S, Williams LT (1991) The human fibroblast growth factor receptor genes: a common structural arrangement underlies the mechanisms for generating receptor forms that differ in their third immunoglobulin domain. Mol Cell Biol 11:46274634.

Kandel J, Bossy-Wetzel E, Radvanyi F, Klagsbrun M, Folkman J, Hanahan D (1991) Ncovascularization is associated with a switch to the export of bFGF in the multistep development of fibrosarcoma. Cell 66:1095-1104.

Kaplan DR, Hempstead BL, Martin ZD, Chao MV, Parada LF (1991) The $t r k$ proto-oncogene product: a signal transducing receptor for nerve growth factor. Science 252:554-558.

Keegan K, Johnson DE, Williams LT, Hayman MJ (1991) Isolation of an additional member of the fibroblast growth factor receptor family, FGFR-3. Proc Natl Acad Sci USA 88:1095-1099.

Klein R, Jing S, Nanduri V, O'Rourke E, Barbacid M (1991a) The trk proto-oncogene encodes a receptor for nerve growth factor. Cell 65:189-197.

Klein R, Nanduri V, Jing S, Lamballe F, Tapley P, Bryant S, Cordon CC, Jones KR, Reichardt LF, Barbacid M (1991b) The trkB tyrosine 
protein kinase is a receptor for brain-derived neurotrophic factor and neurotrophin-3. Cell 66:395-403.

Knüsel B, Winslow JW, Rosenthal A, Burton LE, Seid DP, Nikolics K, Hefti F (1991) Promotion of central cholinergic anad dopaminergic neuron differentiation by brain-derived neurotrophic factor but not neurotrophin 3. Proc Natl Acad Sci USA 88:961-965.

Lipton SA, Wagner JA, Madison RD, D'Amore PA (1988) Acidic fibroblast growth factor enhances regeneration of processes by postnatal mammalian retinal ganglion cells in culture. Proc Natl Acad Sci USA 85:2388-2392.

Marchese C, Rubin J, Ron D, Faggioni A, Torrisi R, Messina A, Frati L, Aaronson SA (1990) Human keratinocyte growth factor activity on proliferation and differentiation of human keratinocytes: differentiation response distinguishes KGF from EGF family. J Cell Physiol 144:326-332.

Marics I, Adelaide J, Raybaud F, Mattei M-G, Coulier F, Planche J, De Lapeyriere O, Birnbaum D (1989) Characterization of the HSTrelated FGF.6 gene, a new member of the fibroblast growth factor gene family. Oncogene 4:335-340.

Miki T, Fleming TP, Bottaro DP, Rubin JS, Ron D, Aaronson SA (1991) Expression cDNA cloning of the KGF receptor by creation of a transforming autocrine loop. Science 251:72-75.

Moore R, Casey G, Brookes S, Dixon M, Peters G, Dickson C (1986) Sequence, topography and protein coding potential of mouse int-2: a putative oncogene activated by mouse mammary tumour virus. EMBO J 5:919-924.

Morrison RS, Sharma A, deVellis J, Bradshaw RA (1986) Basic fibroblast growth factor supports the survival of cerebral cortical neurons in primary culture. Proc Natl Acad Sci USA 83:7537-7541.

Partanen J, Mäkelä TP, Eerola E, Korhonen J, Hirvonen H, Claesson WL, Alitalo K (1991) FGFR-4, a novel acidic fibroblast growth factor receptor with a distinct expression pattern. EMBO J 10:13471354.

Paxinos G, Watson C (1986) The rat brain in stereotaxic coordinates, 2d ed. San Diego: Academic.

Pettmann B, Weibel M, Sensenbrenner M, Labourdette G (1985) Purification of two astroglial growth factors from bovine brain. FEBS Lett 189:102-108.

Radeke MJ, Misko TP, Hsu C, Herzenberg LA, Shooter EM (1987) Gene transfer and molecular cloning of the rat nerve growth factor receptor. Nature 325:593-597.

Rapraeger AC, Krufka A, Olwin BB (1991) Requirement of heparan sulfate for bFGF-mediated fibroblast growth and myoblast differentiation. Science 252:1705-1708.

Renko M, Qurto N, Morimoto T, Rifkin DB (1990) Nuclear and cytoplasmic localization of different basic fibroblast growth factor spccics. J Ccll Physiol 44:108-114.

Schnürch H, Risau W (1991) Differentiating and mature neurons express the acidic fibroblast growth factor gene during chick neural development. Development 111:1143-1154.

Schubert D, Ling N, Baird A (1987) Multiple influences of a heparinbinding growth factor on neuronal development. J Cell Biol 104:635643.

Shipley GD (1986) A serum-free $\left[{ }^{3} \mathrm{H}\right]$ thymidine incorporation assay for the detection of transforming growth factors. J Tissue Cult Methods 10:117-123.

Shipley GD, Ham RG (1981) Improved medium and culture conditions for clonal growth with minimal serum protein and for enhanced serum-free survival of Swiss 3T3 cells. In Vitro 17:656-670.

Soppet D, Escandon E, Maragos J, Middlemas DS, Reid SW, Blair J, Burton LE, Stanton BR, Kaplan DR, Hunter T, Nikolics K, Parada LF (1991) The neurotrophic factors brain-derived neurotrophic factor and neurotrophin-3 are ligands for the trkB tyrosine kinase receptor. Cell 65:895-903.

Squinto SP, Stitt TN, Aldrich TH, Davis S, Bianco SM, Radziejewski C, Glass DJ, Masiakowski P, Furth ME, Valenzuela DM, DiStefano PS, Yancopoulos GD (1991) trkB encodes a functional receptor for brain-derived neurotrophic factor and neurotrophin-3 but not nerve growth factor. Cell 65:885-893.

Taira M, Yoshida T, Miyagawa K, Sakamoto $H$, Terada M, Sugimura $T$ (1987) cDNA sequence of human transforming gene $h$ st and identification of the coding sequence required for transforming activity. Proc Natl Acad Sci USA 84:2980-2984.

Thomas KA (1987) Fibroblast growth factors. FASEB J 1:434-440.

Tooyama I, Akiyama H, McGeer PL, Hara Y, Yasuhara O, Kimura H (1991) Acidic fibroblast growth factor-like immunoreactivity in brain of Alzheimer patients. Neurosci Lett 121:155-158.

Unsicker K, Reichert-Preibsh H, Schmidt R, Pettmann B, Labourdette G, Sensenbrenner M (1987) Astroglial and fibroblast growth factors have neurotrophic functions for cultured peripheral and central nervous system neurons. Proc Natl Acad Sci USA 84:5459-5463.

Vlodavsky I, Bar SR, Ishai MR, Bashkin P, Fuks Z (1991) Extracellular sequestration and release of fibroblast growth factor. Trends Biochem Sci 16:268-271.

Walicke P, Cowan WM, Ueno N, Baird A, Guillemin R (1986) Fibroblast growth factor promotes survival of dissociated hippocampal neurons and enhances neurite extension. Proc Natl Acad Sci USA 83:3012-3016.

Walter P, Lingappa VR (1986) Mechanisms of protein translocation across the endoplasmic reticulum membrane. Annu Rev Cell Biol 2: 499-516.

Wanaka A, Johnson EM, Milbrandt J (1990) Localization of FGF receptor mRNA in the adult rat central nervous system by in situ hybridization. Neuron 5:267-281.

Wilcox BJ, Unnerstall JR (1991) Expression of acidic fibroblast growth factor mRNA in the developing and adult rat brain. Neuron 6:397409.

Woodward WR, Nishi R, Meshul CK, Williams TE, Coulombe M, Eckenstein FP (1992) Nuclear and cytoplasmic localization of basic fibroblast growth factor in astrocytes and CA2 hippocampal neurons. J Neurosci 12:142-152.

Yayon A, Klagsbrun M, Esko JD, Leder P, Ornitz DM (1991) Cell surface, heparin-like molecules are required for binding of basic fibroblast growth factor to its hjigh affinity receptor. Cell 64:841-848.

Zhan X, Bates B, Hu XG, Goldfarb M (1988) The human FGF-5 oncogene encodes a novel protein related to fibroblast growth factors. Mol Cell Biol 8:3487-3495. 